Article

\title{
Analytical Formula for the Ratio of Central to Minimum Film Thickness in a Circular EHL Contact
}

\author{
Petr Sperka *DiD, Ivan Krupka and Martin Hartl \\ Faculty of Mechanical Engineering, Brno University of Technology, Technicka 2896/2, \\ 61669 Brno, Czech Republic; krupka@fme.vutbr.cz (I.K.); hartl@fme.vutbr.cz (M.H.) \\ * Correspondence: sperka@fme.vutbr.cz
}

Received: 23 July 2018; Accepted: 31 August 2018; Published: 7 September 2018

\begin{abstract}
Prediction of minimum film thickness is often used in practice for calculation of film parameter to design machine operation in full film regime. It was reported several times that majority of prediction formulas cannot match experimental data in terms of minimum film thickness. These standard prediction formulas give almost constant ratio between central and minimum film thickness while numerical calculations show ratio which spans from 1 to more than 3 depending on $M$ and $L$ parameters. In this paper, an analytical formula of this ratio is presented for lubricants with various pressure-viscosity coefficients. The analytical formula is compared with optical interferometry measurements and differences are discussed. It allows better prediction, compared to standard formulas, of minimum film thickness for wide range of $M$ and $L$ parameters.
\end{abstract}

Keywords: point contact lubrication; minimum film thickness; prediction formula

\section{Introduction}

Prediction of film thickness represents an important step necessary for up-to-date design of lubricated concentrated contact. Analytical prediction formula can provide simple and rapid estimate of film thickness in elastohydrodynamically lubricated (EHL) contact. Minimum film thickness is used for calculation of film parameter to judge if machine will operate in full or mixed lubrication regime.

Since the pioneering work of Hamrock-Dowson in 1977 [1], numerous prediction formulas have been published in the literature [2-6]. An overview of the prediction formulas can be found in References [7-9]. A common approach is to make full numerical simulations of a contact for some range of conditions and solve regression analysis of film thickness results on operating conditions. These regressions were proven to be surprisingly accurate (considering the time of original formulation), if conditions of contact inlet are isothermal Newtonian. This is especially true for central film thickness, but generally not the case of minimum film thickness [10-14].

Several authors have showed that the ratio between central and minimum film thickness vary significantly with operating parameters [5,15-17]. Moreover, trend of the ratio is not monotonous depending on $L$ parameter, i.e., reaching a local maximum at some value of $L$ parameter. Classic prediction formula defined as a power function of operating conditions cannot represent such phenomenon. For better minimum film thickness formula, it is necessary to search for analytical form that can describe the ratio between central and minimum film thickness. Recently, a parameterization for the ratio of central to minimum film thickness was found for slender contacts (contact size in entrainment direction is much larger than in perpendicular direction) [18].

In this paper, the ratio between central film thickness and minimum film thickness is studied depending on $M$ and $L$ dimensionless parameters. New analytical formula allowing rapid prediction of minimum film thickness in circular point contact is suggested based on numerical simulations. 
The new formula is compared to ratio that come from Hamrock-Dowson equations and optical interferometry measurements.

\section{Material and Methods}

\subsection{Numerical Calculations}

An isothermal Newtonian numerical solution of elastohydrodynamically lubricated (EHL) point contact is assumed. Mathematical model consists of Reynolds equation

$$
\frac{\partial}{\partial x}\left(\frac{\rho h^{3}}{12 \eta} \frac{\partial p}{\partial x}\right)+\frac{\partial}{\partial y}\left(\frac{\rho h^{3}}{12 \eta} \frac{\partial p}{\partial y}\right)-\mathrm{u} \frac{\partial(\rho h)}{\partial x}=0
$$

with boundary conditions $p\left(x_{\mathrm{a}}, y\right)=p\left(x_{\mathrm{b}}, y\right)=p\left(x, y_{\mathrm{a}}\right)=p\left(x, y_{\mathrm{b}}\right)=0$ and the cavitation condition $p(x, y)$ $\geq 0$, film thickness equation

$$
h(x, y)=h_{0}+\frac{x^{2}}{2 R_{x}}+\frac{y^{2}}{2 R_{y}}+\frac{2}{\pi E_{r}} \iint_{-\infty}^{\infty} \frac{p\left(x^{\prime}, y^{\prime}\right) d x^{\prime} d y^{\prime}}{\sqrt{\left(x-x^{\prime}\right)^{2}+\left(y-y^{\prime}\right)^{2}}}
$$

and force balance equation

$$
F=\iint_{-\infty}^{\infty} p(x, y) d x d y
$$

Roelands pressure-viscosity and Dowson-Higginson pressure-density relations have been considered

$$
\begin{gathered}
\eta(p)=\eta_{0} \exp \left[\left(\ln \eta_{0}+9.67\right)\left(\left(1+\frac{p}{0.196 \cdot 10^{9}}\right)^{Z}-1\right)\right] \\
Z=\frac{\alpha_{0} \cdot 0.196 \cdot 10^{9}}{\ln \eta_{0}+9.67} \\
\rho(p)=\rho_{0} \frac{5.9 \cdot 10^{8}+1.34 p}{5.9 \cdot 10^{8}+p}
\end{gathered}
$$

The mathematical model in Equations (1)-(3) was solved by the multilevel multi-integration technique [19]. Second order discretization was assumed. Several mashes with number of grid points from $129 \times 129$ to $1025 \times 1025$ were used and differences between results were monitored to ensure results free of significant grid effect.

Pressure-viscosity response is important for film forming capability of a contact, which is described well by reciprocal asymptomatic isoviscous pressure coefficient $\alpha^{*}$ or film pressure-viscosity coefficient $\alpha_{\text {film }}$ which is proportional to the $\alpha^{*}$ evaluated up to maximum inlet zone pressure [20]. This pressure is, according to Bair et al. [20], considered to be equal to $3 / \alpha^{*}$.

$$
\begin{aligned}
\alpha^{*} & =\left[\int_{0}^{p} \frac{\eta_{0} d p}{\eta(p)}\right]^{-1} \\
\alpha_{\mathrm{film}} & =\alpha^{*}[1-\exp (-3)]
\end{aligned}
$$

The $\alpha_{\text {film }}$ pressure-viscosity parameter is used in the present analytical model of central to minimum film thickness ratio.

\subsection{Film Thickness Measurement}

Film thickness measurements were done on a custom developed ball-on-disk optical tribometer (Brno University of Technology, Brno, Czech republic) [12]. This device measures film thickness in an elastohydrodynamic contact between steel ball and glass (sapphire) disk based on optical interferometry principle. Interferograms are formed between light beams reflected from a ball surface and bottom side of the glass (sapphire) disk coated by thin layer of chromium to ensure high interference contrast. Interferograms are evaluated by Thin film colorimetric interferometry. 
The measurement method uses robust calibration procedure which establishes film thickness/color calibration from monochromatic and chromatic interferogram of a static contact. The calibration procedure and method are described in References [21,22]. The present configuration is without spacer layer which enables evaluation of film thickness in a range of $0-800 \mathrm{~nm}$ with resolution better than $1 \mathrm{~nm}$.

Film thickness was measured for steel on glass and steel on sapphire configurations with reference fluid tri (2-ethylhexyl) trimellitate (TOTM, Sigma-Aldrich, Darmstadt, Germany) as a lubricant. Rheological properties of this fluid were measured in [23]. Basic rheology parameters for test temperature are in Table 1 . Temperature was measured in contact inlet by thermocouple calibrated to more accurate thermistor sensor. Properties of contact bodies are in Table 2.

Table 1. Lubricant parameters.

\begin{tabular}{cc}
\hline & TOTM \\
\hline Test temperature & $30 \pm 0.5^{\circ} \mathrm{C}$ \\
Ambient viscosity & $0.1517 \mathrm{~Pa} \cdot \mathrm{s}$ \\
Initial pressure-viscosity coefficient $\alpha_{0}$ & $23.9 \mathrm{GPa}-1$ \\
Pressure-viscosity coefficient $\alpha^{*}$ & $21.5 \mathrm{GPa}^{-1}$ \\
Film pressure-viscosity coefficient $\alpha_{\text {film }}$ & $20.9 \mathrm{GPa}^{-1}$ \\
\hline
\end{tabular}

Table 2. Properties of contact bodies.

\begin{tabular}{cccc}
\hline & Steel & Glass & Sapphire \\
\hline Radius of curvature & $12.7 \mathrm{~mm}$ & $\infty$ & $\infty$ \\
Young modulus & $206 \mathrm{GPa}$ & $81 \mathrm{GPa}$ & $405 \mathrm{GPa}$ \\
Poisson's ratio & 0.3 & 0.209 & 0.25 \\
\hline
\end{tabular}

\section{Results and Discussion}

A series of EHL contacts with parameters listed in Table 3 were numerically simulated. A convergence better than $10^{-4}$ was required. The ratio of central to minimum film thickness $h_{\mathrm{c}} / h_{\min }$ was evaluated. Contact simulations were done on square grids with different number of points in a range from $129 \times 129$ to $1025 \times 1025$. A difference between results on coarse and finer meshes were evaluated and accepted only when data were with relative difference $<1 \%$ for $M<750$ and $<3 \%$ for $M \geq 750$ to ensure they were free of mesh density influence. All calculated data of ratios are listed in the Tables A1-A3.

Table 3. Range of numerically simulated conditions.

\begin{tabular}{ccccc}
\hline $\boldsymbol{M}$ & $\boldsymbol{L}$ & $\boldsymbol{\alpha}_{\mathbf{0}}$ & $\boldsymbol{\alpha}^{*}$ & $\boldsymbol{\alpha}_{\text {film }}$ \\
\hline $2,5,10,20,50,100$, & $1,2,5,7,10,15,20$, & 11,22, & $8.2,20.3$, & $8.7,20.6$, \\
$200,500,750,1000$ & 25,30 & $33 \mathrm{GPa}^{-1}$ & $32.6 \mathrm{GPa}^{-1}$ & $32.7 \mathrm{GPa}^{-1}$ \\
\hline
\end{tabular}

Film thickness ratios were compared to published results in $[17,18]$. The average difference (Table 4 ) is $4.4 \%$ and $3.5 \%$, respectively. Because it was found in present results that film thickness ratio depends on pressure-viscosity coefficient, besides $M$ and $L$ parameters, certain part of the deviations can come from differences in this coefficient. The values of pressure-viscosity, for which the film thickness ratios were obtained, are not clear in the literature sources.

Table 4. Comparison of present $h_{\mathrm{c}} / h_{\min }$ results to published ones.

\begin{tabular}{cccc}
\hline & Comparison 1 & Comparison 2 & Comparison 3 \\
\hline Published result & Venner [18] & Venner [18] & Chevalier [17] \\
Present result & numerical results & analytical model & analytical model \\
Average difference & $4.4 \%$ & $4.3 \%$ & $3.5 \%$ \\
\hline
\end{tabular}


Figure 1 shows a domain of current simulations, operating points of experiments and domain of parameters on which Hamrock-Dowson film thickness equations were established. These equations are one of the most employed in EHL field, therefore, it was chosen for comparison. According to [1], the central and minimum film thickness can be predicted by

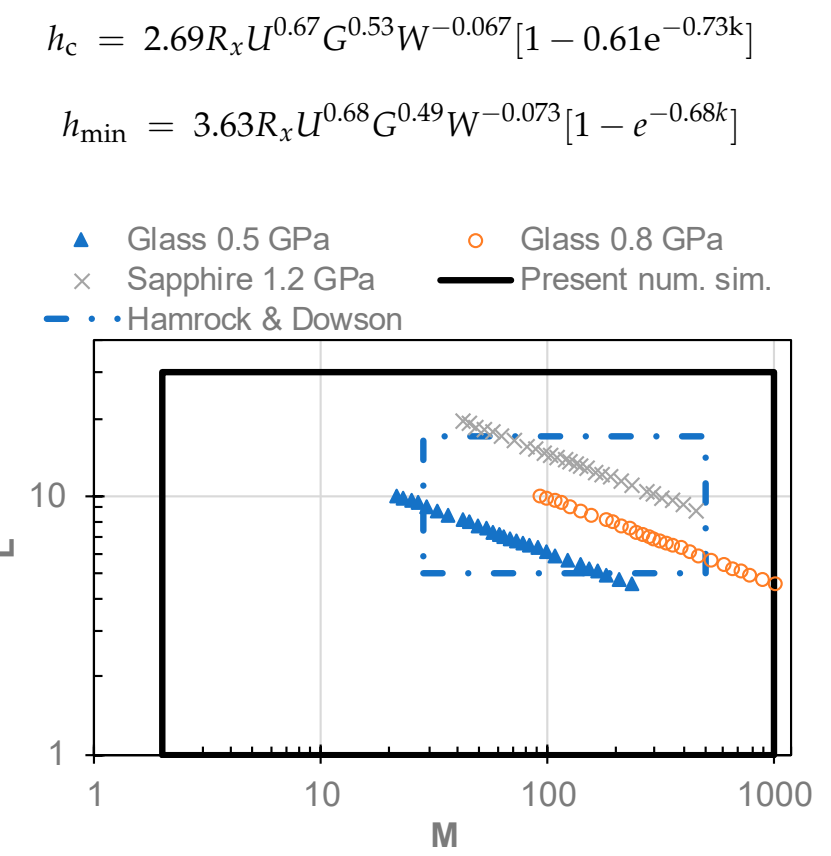

Figure 1. Present calculation domain compared to operating points of experiments and domain for regression of Hamrock-Dowson formulas.

Figure 2 shows a dependency of film thickness ratio $h_{\mathrm{c}} / h_{\min }-1$ on $M$ parameter for three fixed $L$ values. Figure 3 presents a dependency of film thickness ratio $h_{\mathrm{c}} / h_{\min }$ on $L$ parameter for three fixed $M$ values. Both plots are for $\alpha_{\text {film }}=20.6 \mathrm{GPa}^{-1}$. The dependency of the film thickness ratio monotonically rises on $M$ while there is a local maximum in dependency on parameter $L$. This local maximum is around $L=5$ and seems to slightly change with increasing $M$ parameter. The ratio approaches 1 for low $L$ and $M$ values.

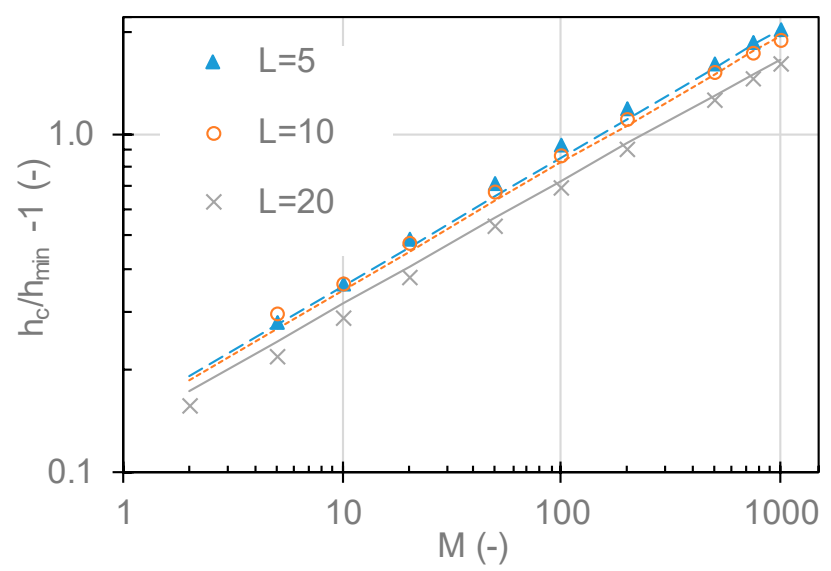

Figure 2. Dependency of $h_{\mathrm{c}} / h_{\mathrm{min}}$ ratio on $M$ parameter for $\alpha_{\text {film }}=20.6 \mathrm{GPa}^{-1}$.

Since axes in Figure 2 are in log scale, the points follow power trend with parameter M. When $x$ axis in Figure 3 is transformed to log scale, the points follow close to quadratic trend. Therefore, the complete dataset was fitted to Equation (11), where $a, b, c$ and $d$ are fitting constants.

$$
h_{\mathrm{c}} / h_{\min }=1+a \cdot M^{\mathrm{b}}-\sqrt{M}[c \cdot \ln (L)-d]^{2}
$$




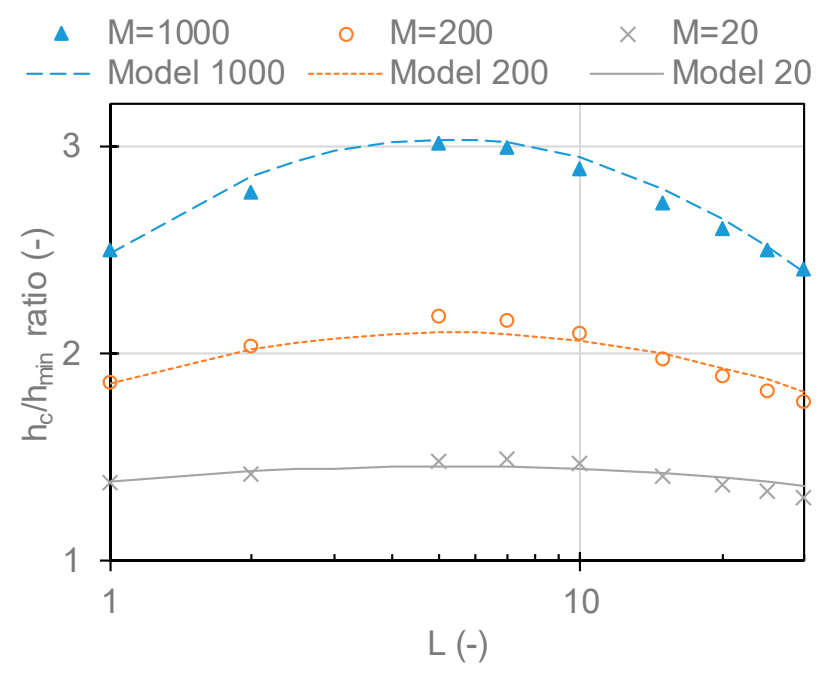

Figure 3. Dependency of $h_{\mathrm{c}} / h_{\mathrm{min}}$ ratio on $L$ parameter for $\alpha_{\text {film }}=20.6 \mathrm{GPa}^{-1}$.

The effect of different reduced radii of curvature, elastic properties or lubricant ambient viscosity on the ratio was checked by numerical simulations and no effect was found; therefore, the results are considered independent of chosen geometry and elasticity. On the other hand, it was found that film thickness ratio is sensitive to pressure-viscosity coefficient; simulations were done for three values (Table 3) in a range from 8.7 to $32.7 \mathrm{GPa}^{-1}$. It corresponds to the pressure-viscosity coefficient according definition in Equation (8) published by Bair [23]. It was shown that it is able precisely capture relation of viscosity on pressure necessary for film thickness formation in EHL contacts. According Table 3, the values of $\alpha_{\text {film }}$ are not far from $\alpha^{*}$ coefficient. The analytical model fitted to the results is shown in Figure 4 in a form of contour plot on the left side and residuals from fitting in the right plots. Final form of analytical model of film thickness ratio which depends on $M$ and $L$ parameters and $\alpha_{\text {film }}$ pressure-viscosity coefficient is given by Equation (12). Quality parameters of the fits shown in Figure 4 are listed in Table 5; root mean square of the error is $0.03-0.04$ which represents about $2 \%$ of average film thickness ratio. Equation (12) was plotted as a model in Figures 2-5.

$$
h_{\mathrm{c}} / h_{\min }=1+0.1 \cdot \alpha_{\mathrm{film}}{ }^{0.128} \cdot M^{0.38}-\sqrt{M}\left[\frac{\alpha_{\mathrm{film}}{ }^{0.2} \cdot \ln (L)-3}{22.7}\right]^{2}
$$

where $\alpha_{\text {film }}$ is in $\mathrm{GPa}^{-1}$. The equation is repeated together with list of assumptions and conditions for which it was obtained in Appendix B.

According Equation (12) and Figure 2, the pressure-viscosity coefficient modifies constant in power trend on $M$ parameter, but the power slope remains the same. In terms of dependency on $L$ parameter, the pressure-viscosity coefficient shifts the position of maximum peak, as it is shown in Figure 5.

Table 5. Parameters of fitting goodness.

\begin{tabular}{cccc}
\hline$\alpha_{\text {film }}$ & $\mathbf{8 . 7} \mathbf{G P a}^{-1}$ & $\mathbf{2 0 . 6} \mathrm{GPa}^{-\mathbf{1}}$ & $\mathbf{3 2 . 7 ~ G P a}^{-\mathbf{1}}$ \\
\hline Root mean square error (RMSE) & 0.031 & 0.038 & 0.039 \\
RMSE in \% & $1.7 \%$ & $2.0 \%$ & $2.1 \%$ \\
\hline
\end{tabular}



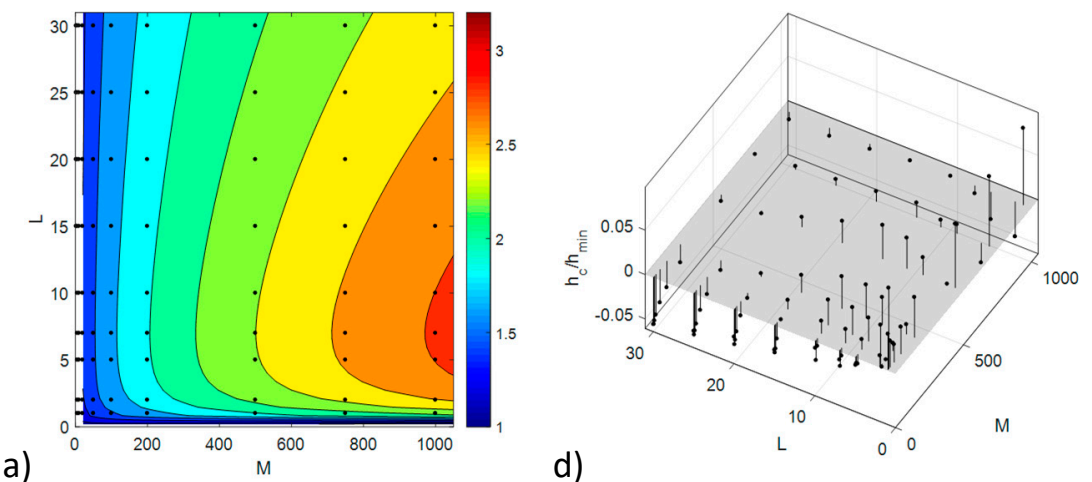

d)
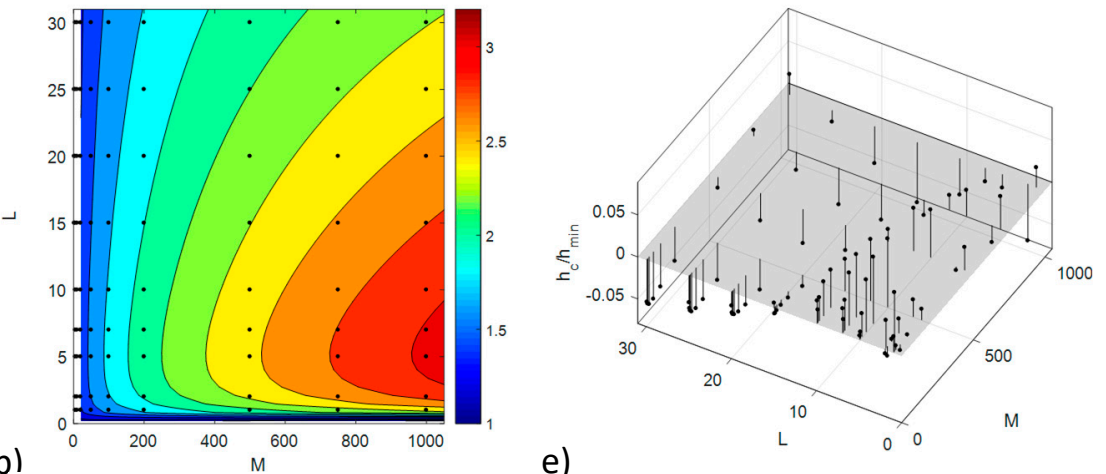

b

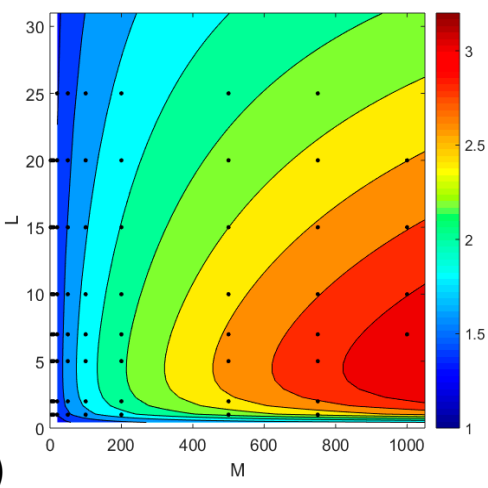

e)

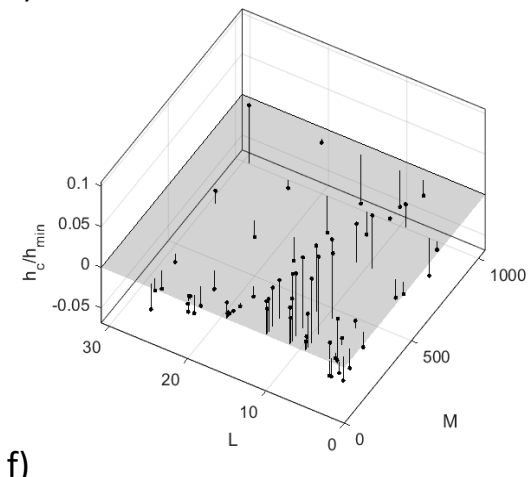

Figure 4. Numerical results of film thickness ratio $h_{\mathrm{c}} / h_{\min }$ fitted by analytical function: (a-c) contours plots; and (d-f) fitting residuals $\left((\mathbf{a}, \mathbf{d})\right.$ for $\alpha_{\text {film }}=8.7 \mathrm{GPa}^{-1}$; $(\mathbf{b}, \mathbf{e})$ for $\alpha_{\text {film }}=20.6 \mathrm{GPa}^{-1}$; and $\left.(\mathbf{c}, \mathbf{f}) \alpha_{\text {film }}=32.7 \mathrm{GPa}^{-1}\right)$.

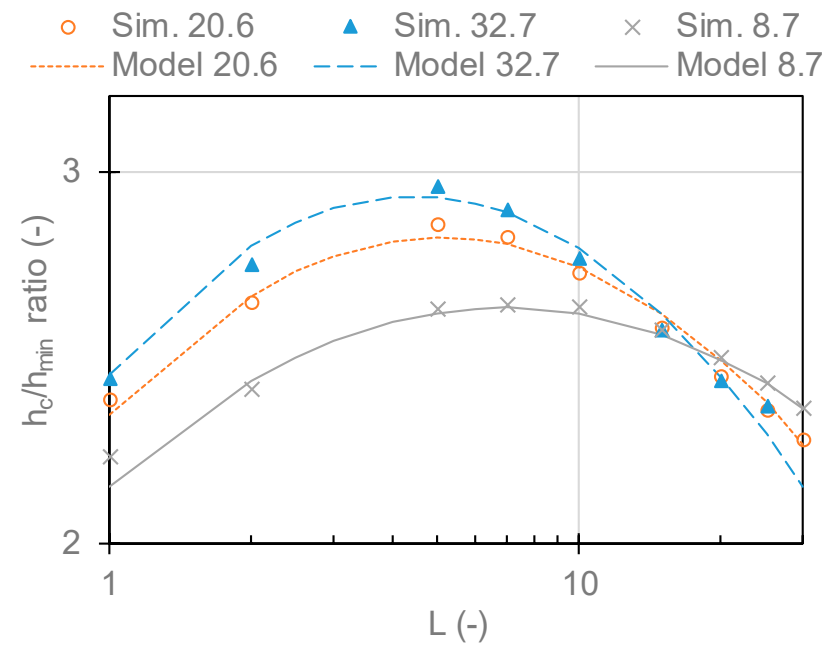

Figure 5. Dependency of $h_{\mathrm{c}} / h_{\text {min }}$ ratio on $L$ for $M=750$ and all three simulated $\alpha_{\text {film. }}$. 
Next to the simulations, a film thickness was measured at three levels of Hertzian pressure. It was a contact of steel against glass for 26 and $112 \mathrm{~N}$ giving Hertzian pressure of 0.493 and $0.799 \mathrm{GPa}$, respectively, and a contact of steel with sapphire loaded by $63 \mathrm{~N}$ giving 1.186 GPa. Central film thickness was evaluated and corrected for refractive index change with pressure, as in [10], while minimum film thickness was left without correction since the place of minimum is expected to be in the area of low pressure. A range of speeds from 100 to $1200 \mathrm{~mm} / \mathrm{s}$ was measured and $h_{\mathrm{c}} / h_{\text {min }}$ ratio was calculated.

In Figure 6, there is a comparison of measured ratios with predictions given by present model (Equation (12)) and prediction according Hamrock-Dowson formulas (Equations (9) and (10)). The Hamrock-Dowson formulas gives almost constant $h_{\mathrm{c}} / h_{\mathrm{min}}$ ratio which is close to measured value only for 0.5 and $1.2 \mathrm{GPa}$ and small range of speed around $500 \mathrm{~mm} / \mathrm{s}$. Present model gives good prediction of trends in all cases. Quantitatively, there is very good agreement for $1.2 \mathrm{GPa}$ and not as good agreement for 0.5 and $0.8 \mathrm{GPa}$. Average differences between measurement and predictions are listed in Table 6. It shows that present formula predicts the ratio within $11 \%$, while Hamrock-Dowson is off by up to $37 \%$.

Table 6. Average difference of measurement and $h_{\mathrm{c}} / h_{\min }$ ratio estimation by Hamrock-Dowson (H\&D) and present analytical formula.

\begin{tabular}{cccc}
\hline & Case 1 & Case 2 & Case 3 \\
\hline Measurement pressure & $0.5 \mathrm{GPa}$ & $0.8 \mathrm{GPa}$ & $1.2 \mathrm{GPa}$ \\
H\&D formulas (Equations (9) and (10)) & $12.9 \%$ & $36.5 \%$ & $9.7 \%$ \\
Present formula (Equation (12)) & $8.8 \%$ & $10.6 \%$ & $2.2 \%$ \\
\hline
\end{tabular}

Ratios calculated from measured data having uncertainties can produce a large error when thin films are studied. Therefore, conditions with $h_{\min }$ film thickness above $60 \mathrm{~nm}$ and $h_{\mathrm{c}}$ film thickness above $140 \mathrm{~nm}$ were considered. Measurements were repeated three times for each pressure; ratios were evaluated independently and averaged. Average standard deviation of measured ratios is 0.028 which corresponds to $1.3 \%$. Measurement has another error which comes from the fact that minimum film thickness is evaluated as a global minimum in a contact. Every ball has a certain roughness $(3 \mathrm{~nm}$ RMS in present measurement); therefore, the evaluated $h_{\mathrm{min}}$ is practically always picked on a peak of roughness. As a result, measured minimum film thickness tends to be systematically evaluated as lower than the true value. Typical in-contact RMS value of roughness was $0.6 \mathrm{~nm}$, therefore, distance of mid plane to highest peaks was about $1.8 \mathrm{~nm}$ which makes average impact on film thickness ratio 0.03 , i.e., much less then observed difference.

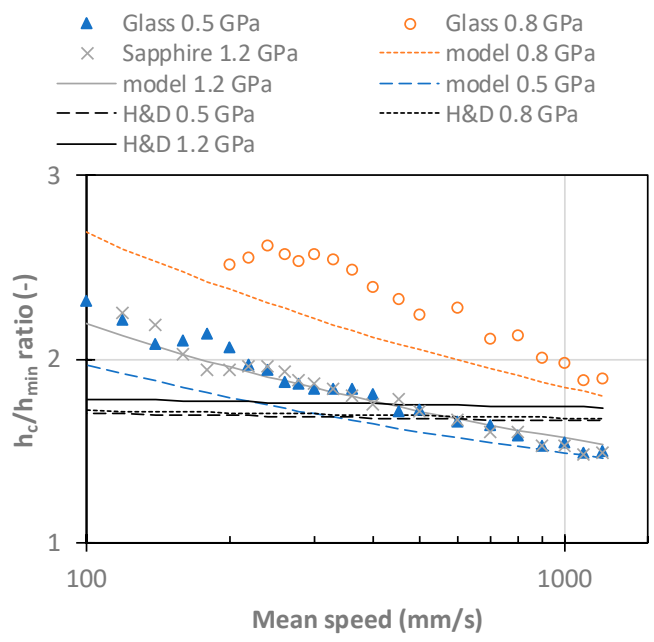

Figure 6. Comparison of measured $h_{\mathrm{c}} / h_{\mathrm{min}}$ ratios with prediction from Hamrock-Dowson equations (Equations (8) and (9)) and present analytical model given by Equation (12). 
As shown in Figures 3 and 5, present model (Equation (12)) cannot fully capture the highest values of simulated ratios. The highest fit residuals are between $L$ parameter 5 and 7 where experimental conditions of 0.5 and $0.8 \mathrm{GPa}$ are localized (see Figure 1). Nevertheless, these local residuals of the fit are up to 0.08 , thus they cannot fully explain differences in measurements.

In present study, Roelands model for pressure-viscosity relationship and Dowson-Higginson relation of density dependency on pressure were used. These models have limitations. Various lubricants can behave differently, especially under high pressure. Nevertheless, it is commonly expected that low pressure rheology is important for film forming capabilities. Furthermore, real lubricant compressibility influences central film thickness, which affects the film thickness ratio.

\section{Conclusions}

The ratio between central and minimum film thickness in a circular EHL contact varies between 1 and 3.16 for considered range of conditions. This trend cannot be captured by widely used prediction formulas employing (monotonous) power function, since dependency on $L$ parameter has a local extreme at $L=\exp \left(3 / \alpha_{\text {film }}{ }^{0.2}\right)$. Isothermal Newtonian numerical simulations were used to compute the film thickness ratio for wide range of $M$ and $L$ parameters and three pressure-viscosity coefficients. A new analytical formula for fitting of the ratio is presented. Final regression of numerical simulations has root mean square error of 0.036 , i.e., $1.9 \%$. A comparison with measurement showed good trend agreement and quantitatively smaller difference than Hamrock-Dowson formulas. This new formula together with published formula for central film thickness can be used for minimum thickness prediction.

Author Contributions: P.S. conducted experiments and calculated simulation data; P.S. and I.K. analyzed the data; I.K. and M.H. developed measurement method, provided consultation of results and obtained funding for research; P.S. wrote the paper.

Funding: This research was funded by the Ministry of Education, Youth and Sports under the National Sustainability Program I (Project LO1202).

Conflicts of Interest: All authors declare no conflict of interest.

\section{Nomenclature}

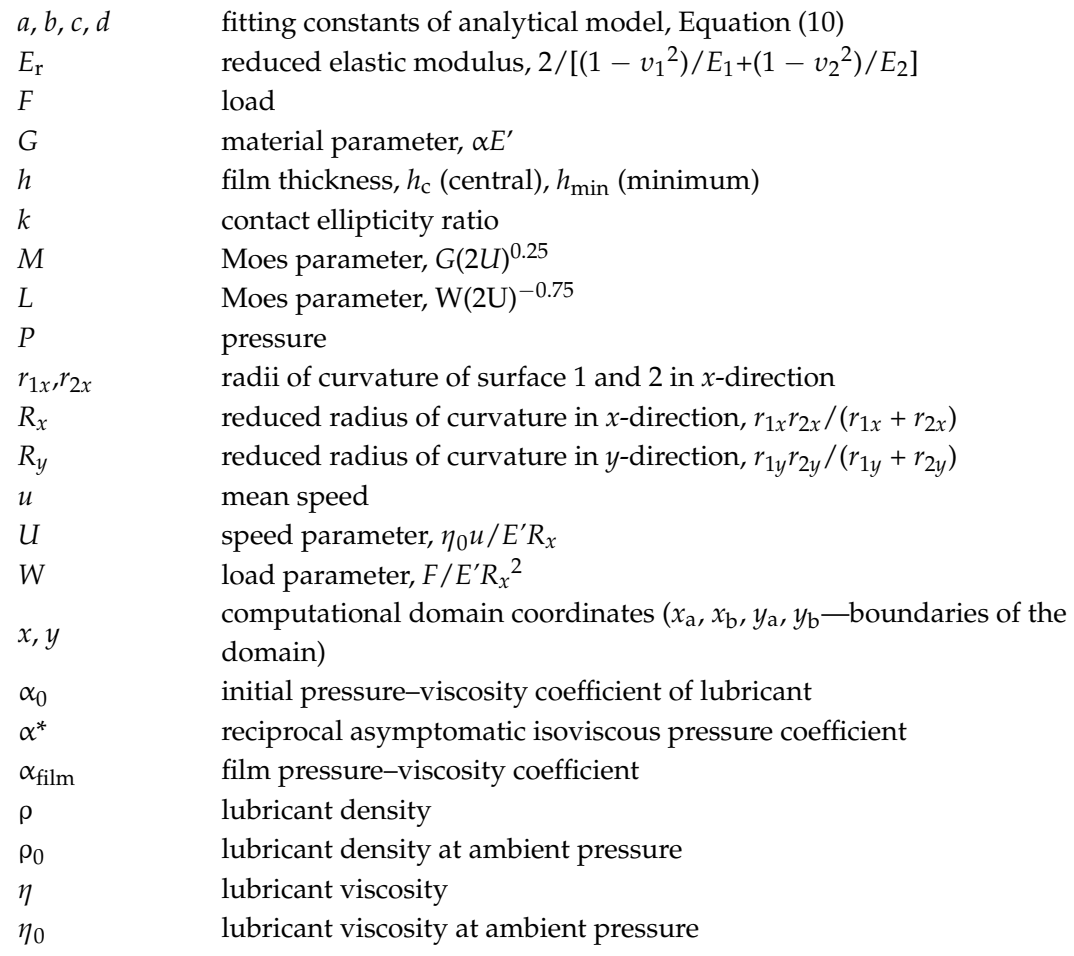




\section{Appendix A. Simulation Data}

Table A1. Ratios of central film thickness to minimum film thickness in a point contact for $\alpha_{\text {film }}=8.7 \mathrm{GPa}^{-1}$.

\begin{tabular}{|c|c|c|c|c|c|c|c|c|c|c|c|}
\hline & \multicolumn{10}{|c|}{$M$} \\
\hline & & 2 & 5 & 10 & 20 & 50 & 100 & 200 & 500 & 750 & 1000 \\
\hline \multirow{9}{*}{$L$} & 1 & & 1.24 & 1.35 & 1.36 & 1.48 & 1.61 & 1.79 & 2.08 & 2.23 & 2.35 \\
\hline & 2 & & 1.24 & 1.34 & 1.38 & 1.53 & 1.70 & 1.90 & 2.24 & 2.41 & 2.55 \\
\hline & 5 & & 1.23 & 1.31 & 1.40 & 1.59 & 1.78 & 2.01 & 2.41 & 2.63 & 2.77 \\
\hline & 7 & & 1.23 & 1.30 & 1.40 & 1.60 & 1.79 & 2.03 & 2.43 & 2.64 & 2.81 \\
\hline & 10 & & 1.23 & 1.29 & 1.40 & 1.59 & 1.78 & 2.02 & 2.42 & 2.63 & 2.80 \\
\hline & 15 & 1.14 & 1.21 & 1.28 & 1.38 & 1.56 & 1.74 & 1.97 & 2.36 & 2.57 & 2.74 \\
\hline & 20 & 1.13 & 1.19 & 1.26 & 1.36 & 1.53 & 1.70 & 1.92 & 2.30 & 2.50 & 2.65 \\
\hline & 25 & 1.12 & 1.18 & 1.25 & 1.34 & 1.50 & 1.66 & 1.87 & 2.23 & 2.43 & 2.58 \\
\hline & 30 & 1.10 & 1.17 & 1.24 & 1.32 & 1.48 & 1.63 & 1.83 & 2.17 & 2.36 & 2.50 \\
\hline
\end{tabular}

Table A2. Ratios of central film thickness to minimum film thickness in a point contact for $\alpha_{\text {film }}=20.6 \mathrm{GPa}^{-1}$.

\begin{tabular}{|c|c|c|c|c|c|c|c|c|c|c|c|}
\hline & \multicolumn{10}{|c|}{$M$} \\
\hline & & 2 & 5 & 10 & 20 & 50 & 100 & 200 & 500 & 750 & 1000 \\
\hline \multirow{9}{*}{$L$} & 1 & & 1.25 & 1.37 & 1.39 & 1.52 & 1.67 & 1.87 & 2.20 & 2.38 & 2.50 \\
\hline & 2 & & 1.25 & 1.37 & 1.42 & 1.61 & 1.81 & 2.04 & 2.43 & 2.64 & 2.78 \\
\hline & 5 & & 1.28 & 1.36 & 1.49 & 1.71 & 1.93 & 2.18 & 2.62 & 2.85 & 3.02 \\
\hline & 7 & & 1.30 & 1.37 & 1.49 & 1.71 & 1.92 & 2.17 & 2.60 & 2.82 & 3.00 \\
\hline & 10 & & 1.29 & 1.36 & 1.47 & 1.67 & 1.86 & 2.10 & 2.51 & 2.73 & 2.90 \\
\hline & 15 & 1.19 & 1.25 & 1.32 & 1.42 & 1.59 & 1.77 & 1.98 & 2.37 & 2.58 & 2.73 \\
\hline & 20 & 1.16 & 1.22 & 1.29 & 1.38 & 1.53 & 1.69 & 1.90 & 2.25 & 2.45 & 2.61 \\
\hline & 25 & 1.14 & 1.20 & 1.26 & 1.34 & 1.49 & 1.64 & 1.83 & 2.17 & 2.36 & 2.51 \\
\hline & 30 & & 1.18 & 1.24 & 1.31 & 1.45 & 1.59 & 1.78 & 2.10 & 2.28 & 2.42 \\
\hline
\end{tabular}

Table A3. Ratios of central film thickness to minimum film thickness in a point contact for $\alpha_{\text {film }}=32.7 \mathrm{GPa}^{-1}$.

\begin{tabular}{|c|c|c|c|c|c|c|c|c|c|c|c|}
\hline & \multicolumn{10}{|c|}{$M$} \\
\hline & & 2 & 5 & 10 & 20 & 50 & 100 & 200 & 500 & 750 & 1000 \\
\hline \multirow{8}{*}{$L$} & 1 & & 1.25 & 1.37 & 1.40 & 1.54 & 1.70 & 1.90 & 2.25 & 2.44 & \\
\hline & 2 & & 1.26 & 1.38 & 1.44 & 1.65 & 1.86 & 2.11 & 2.52 & 2.75 & \\
\hline & 5 & & 1.30 & 1.39 & 1.53 & 1.77 & 1.99 & 2.27 & 2.72 & 2.96 & \\
\hline & 7 & & 1.33 & 1.40 & 1.53 & 1.76 & 1.97 & 2.23 & 2.67 & 2.89 & 3.09 \\
\hline & 10 & & 1.32 & 1.39 & 1.51 & 1.70 & 1.90 & 2.13 & 2.54 & 2.77 & 2.95 \\
\hline & 15 & 1.21 & 1.27 & 1.34 & 1.44 & 1.61 & 1.78 & 1.99 & 2.37 & 2.57 & 2.73 \\
\hline & 20 & 1.18 & 1.24 & 1.33 & 1.41 & 1.54 & 1.70 & 1.90 & 2.24 & 2.44 & 2.59 \\
\hline & 25 & & & & 1.35 & 1.51 & 1.64 & 1.83 & 2.15 & 2.37 & \\
\hline
\end{tabular}

\section{Appendix B. Film Thickness Ratio Equation and Table with Assumptions}

$$
h_{\mathrm{c}} / h_{\min }=1+0.1 \cdot \alpha_{\mathrm{film}}{ }^{0.128} \cdot M^{0.38}-\sqrt{M}\left[\frac{\alpha_{\mathrm{film}}{ }^{0.2} \cdot \ln (L)-3}{22.7}\right]^{2}
$$

where $\alpha_{\text {film }}$ is in $\mathrm{GPa}^{-1}$. This equation was obtained under contact assumptions and for the range of conditions listed in the following Table A4. 
Table A4. List of contact assumptions and the range of conditions in the numerical analyses.

Isothermal Newtonian (without shear thinning effects) conditions

Circular point contact

Smooth surface

Lubricant rheology governed by Roelands pressure-viscosity and

Dowson-Higginson pressure-density relationships

$M$ parameter from 2 to 1000

$L$ parameter from 1 to 30

Pressure-viscosity coefficient $\alpha_{\text {film }}$ from 8.7 to $32.7 \mathrm{GPa}^{-1}$

\section{References}

1. Hamrock, B.J.; Dowson, D. Isothermal elastohydrodynamic lubrication of point contacts: Part III-Fully flooded results. J. Lubr. Technol. 1977, 99, 264-275. [CrossRef]

2. Evans, P.; Snidle, R. The isothermal elastohydrodynamic lubrication of spheres. ASME J. Lubr. Technol. 1981, 103, 547-557. [CrossRef]

3. Chittenden, R.J.; Dowson, D.; Dunn, J.F.; Taylor, C.M. A theoretical analysis of the isothermal elastohydrodynamic lubrication of concentrated contacts-Part 2: General case, with lubricant entrainment along either principal axis of the hertzian contact ellipse or at some intermediate angle. Proc. R. Soc. Lond. A 1985, 397, 271-294. [CrossRef]

4. Hooke, C.J. Minimum film thickness in lubricated point contacts operating in the elastic piezoviscous regime. Proc. Inst. Mech. Eng. Part C J. Eng. Tribol. 1988, 202, 73-84.

5. Nijenbanning, G.C.H.H.; Venner, C.H.; Moes, H. Film thickness in elastohydrodynamically lubricated elliptic contacts. Wear 1994, 176, 217-229. [CrossRef]

6. Masjedi, M.; Khonsari, M.M. On the effect of surface roughness in point-contact EHL: Formulas for film thickness and asperity load. Tribol. Int. 2015, 82, 228-244. [CrossRef]

7. Van Leeuwen, $\mathrm{H}$. The determination of the pressure-viscosity coefficient of a lubricant through an accurate film thickness formula and accurate film thickness measurements. Proc. Inst. Mech. Eng. Part J J. Eng. Tribol. 2009, 223, 1143-1163. [CrossRef]

8. Van Leeuwen, $\mathrm{H}$. The determination of the pressure-viscosity coefficient of a lubricant through an accurate film thickness formula and accurate film thickness measurements. Part 2: High L values. Proc. Inst. Mech. Eng. Part J J. Eng. Tribol. 2011, 225, 449-464. [CrossRef]

9. Wheeler, J.D.; Vergne, P.; Fillot, N.; Philippon, D. On the relevance of analytical film thickness EHD equations for isothermal point contacts: Qualitative or quantitative predictions? Friction 2016, 4, 369-379. [CrossRef]

10. Krupka, I.; Hartl, M.; Poliscuk, R.; Cermak, J.; Liska, M. Experimental evaluation of EHD film shape and its comparison with numerical solution. J. Tribol. 2000, 122, 689-696. [CrossRef]

11. Krupka, I.; Hartl, M.; Poliscuk, R.; Liska, M. Experimental study of central and minimum elastohydrodynamic film thickness by colorimetric interferometry technique. Tribol. Trans. 2000, 43, 611-618. [CrossRef]

12. Hartl, M.; Krupka, I.; Poliscuk, R.; Liska, M.; Molimard, J.; Querry, M.; Vergne, P. Thin film colorimetric interferometry. Tribol. Trans. 2001, 44, 270-276. [CrossRef]

13. Křupka, I.; Hartl, M.; Liška, M. Influence of contact pressure on central and minimum film thickness within ultrathin film lubricated contacts. J. Tribol. 2005, 127, 890-892. [CrossRef]

14. Biboulet, N.; Sperka, P.; Venner, C.H.; Lubrecht, A.A.; Krupka, I. Obtaining the pressure spike and maximum shear stress from optical interferometry data. Tribol. Int. 2013, 62, 1-7. [CrossRef]

15. Venner, C.H. Multilevel Solution of the EHL Line and Point Contact Problems. Ph.D. Thesis, Twente University, Enschede, The Netherlands, 1991.

16. Venner, C.H.; Napel, W.E. Multilevel solution of the elastohydrodynamically lubricated circular contact problem, part II: Smooth surface results. Wear 1992, 152, 369-381. [CrossRef]

17. Chaomleffel, J.P.; Dalmaz, G.; Vergne, P. Experimental results and analytical predictions of EHL film thickness. Tribol. Int. 2007, 40, 1543-1552. [CrossRef]

18. Venner, C.H.; Lubrecht, A.A. Revisiting film thickness in slender elasto-hydrodynamically lubricated contacts. Proc. Inst. Mech. Eng. Part C J. Eng. Tribol. 2010, 224, 2549-2558. [CrossRef]

19. Venner, C.H.; Lubrecht, A.A. Multi-Level Methods in Lubrication; Elsevier: Amsterdam, The Netherlands, 2000. 
20. Bair, S.; Liu, Y.; Wang, Q.J. The pressure-viscosity coefficient for Newtonian EHL film thickness with general piezoviscous response. J. Tribol. 2006, 128, 624-631. [CrossRef]

21. Hartl, M.; Krupka, I.; Liska, M. Differential colorimetry: Tool for evaluation of chromatic interference patterns. Opt. Eng. 1997, 36, 2384-2391. [CrossRef]

22. Hartl, M.; Krupka, I.; Poliscuk, R.; Liska, M. An automatic system for real-time evaluation of EHD film thickness and shape based on the colorimetric interferometry. Tribol. Trans. 1999, 42, 303-309. [CrossRef]

23. Bair, S. The temperature and pressure dependence of viscosity and volume for two reference liquids. Lubr. Sci. 2016, 28, 81-95. [CrossRef]

(C) 2018 by the authors. Licensee MDPI, Basel, Switzerland. This article is an open access article distributed under the terms and conditions of the Creative Commons Attribution (CC BY) license (http:/ / creativecommons.org/licenses/by/4.0/). 